\title{
Cidade de Deus: uma sintaxe da violência
}

Marina Machado Rodrigues

Universidade do Estado do Rio de Janeiro

RESUMO: O PRESENTE TRABALHO OBJETIVA ESTUDAR AS RELAÇÕES ENTRE A VIOLÊNCIA URBANA E A FICÇÃO PÓS-MODERNA NO BEST-SELLER DE PAULO LINS, CIDADE DE DEUS. PARA A LEITURA E COMPREENSÃO DA REALIDADE FOCADA NO ROMANCE, PROPUSEMOS UMA REFLEXÃO SOBRE POLÍTICA E ESTÉTICA E SEUS INFLUXOS NA PRODUÇÃO ARTÍSTICA E CULTURAL DA PÓS-MODERNIDADE.

ABSTRACT: THE PRESENT PAPER DEALS WITH THE RELATIONS BETWEEN URBAN VIOLENCE AND POST-MODERN FICTION IN PAULO LINS BEST-SELLER, CIDADE DE DEUS. FOR A BETTER READING AND UNDERSTANDING OF THE REALITY PORTRAYED IN THE BOOK, WE PROPOSE A REFLECTION ON POLITIC AND AESTHETIC AND ITS INFLUX ON POST-MODERN ARTISTIC AND CULTURAL PRODUCTION.

PALAVRAS-CHAVE: VIOLÊNCIA URBANA - FICÇÃO PÓS-MODERNA - PAULO LINS - POLITICA E ESTÉTICA

KEY-WORDS: URBAN VIOLENCE - POST-MODERN FICTION - PAULO LINS - POLITIC AND AESTHETIC 
ais do que o problema da exclusão, nossa época assiste à identificação entre pobreza e criminalização. Os investimentos de alcance social têm sido sistematicamente substituídos pelos dispositivos de coerção, que isolam um terço da população mundial em guetos dos quais em geral não há saída.

Cidade de Deus narra a história dos proscritos. Baseado em fatos reais, o romance retrata o cotidiano de uma favela carioca, o tráfico de drogas, a guerra entre quadrilhas e a opressão de uma classe tanto pelas facções criminosas como pela violência institucionalizada, inaugurando uma sintaxe da violência.

À moda dos relatos épicos, o narrador faz sua invocação à poesia para que ilumine um discurso cujo objetivo é descrever a crueza de um mundo alheio a ela, em que a golpes de realidade a vida cava fulcros profundos na carne dos seus habitantes. Assim é que arrisca "a prosa mesmo com bala atravessando os fonemas". O narrador sabe que a realidade interdita as palavras e que o verbo "cambaleia baleado" porque ali "falha a fala. Fala a bala".

Também como nas epopéias, o romance se inicia com a ação ao meio, em plena guerra entre os bandos de Zé Miúdo e Bonito, recorrendo ao flashback para resgatar a origem do lugar e a fonte do conflito. $\mathrm{Na}$ descrição da chegada dos novos moradores à Cidade de Deus, a justaposição de imagens expressa, através da metonímia, pedaços de um mundo multiforme e imperfeito; um microcosmo social que reflete a estratificação do macrocosmo de que se origina. O narrador faz um inventário antropológico daquela comunidade, na qual se misturam religiões, hábitos, trastes, lazer, moléstias, culturas, a falta de esperança, a revolta, a opressão e a desvalia que caracterizam o modo de vida das classes pobres. $\mathrm{O}$ acúmulo e a aproximação de significantes tão díspares revela, do ponto de vista do significado, a desorganização e a desqualificação de uma população que parece ter sido despejada naquele lugar, como se despeja o lixo nos lixões:

Os novos moradores levaram lixo, latas, cães vira-latas, exus e pombagiras em guias intocáveis, dias para se ir a luta, soco antigo para ser descontado, restos de raiva de tiros, noites para velar cadáveres, resquícios de enchentes, biroscas, feiras de quartas-feiras e as de domingos, vermes velhos em barrigas infantis, revólveres, orixás enroscados em pescoços, frango de despacho, samba de enredo e sincopado, jogo do bicho, fome, traição, mortes, jesus cristos em cordões arrebentados, forró quente para ser dançado, lamparina de azeite para iluminar o santo, fogareiros, pobreza para querer enriquecer, olhos para nunca ver, nunca 
dizer, nunca olhos e peito para encarar a vida, despistar a morte, rejuvenescer a raiva, ensangüentar destinos, fazer a guerra e para ser tatuado. (LINS, 2002: 16)

Os moradores traziam no rosto a marca das enchentes, mas também a esperança, corroída ironicamente pela canção "Cidade Maravilhosa”, entoada na chegada, como se o novo local inscrevesse a possibilidade de resgate da felicidade falhada e da dignidade perdida a que a miséria se sobrepõe. Para as crianças, os grandes espaços, o contato com a natureza, a infinidade de descobertas que a Cidade de Deus proporcionava era a tradução da liberdade e da felicidade sonhadas. Para os adultos, representava a realização do anseio acalentado por toda a vida: o abrigo de um teto, ainda que sob condições adversas. Para todos, porém, o lugar se transformou na experiência viva do Inferno.

O primeiro capítulo conta as "aventuras" do trio Ternura - Inferninho, Martelo e Tutuca, que optaram pela vida bandida, inconformados com a posição de excluídos a que a origem os relegara. Subvertendo o estilo épico, a narrativa não os vê como heróis, mas como vítimas de um contexto perverso que molda os destinos de uma classe fadada à desgraça. Aqueles que se revoltam contra esse destino quase sempre só encontram espaço na criminalidade. O texto, contudo, não os submete à ótica determinista, já que inscreve a salvação de alguns de seus personagens. A saída pode ser encontrada através da qualificação profissional, como Busca-Pé, que se torna fotógrafo e abandona o gueto, ou mesmo pela via da religião, que para alguns representa o único refúgio seguro contra o mal.

Fornecendo as justificativas sociais e psicológicas para a revolta que marcará a personalidade de Inferninho, o narrador traça a história familiar do bandido, que escolhe o seu caminho ainda criança. Filho de pai alcoólatra e mãe prostituta, tinha como única referência afetiva a avó, que morreu quando ele era ainda criança. Se a avó fosse viva, talvez não tivesse escolhido a vida de bandido e, por ela, quem sabe, tivesse virado "otário", refletia o personagem. Mas trocando a impotência pela ação, recusa a resignação. Marcadas pelo ódio, suas ações serão sempre reações - ecos da revolta contra a vida e o destino miseráveis:

Por fim, Inferninho, depois de fazer a bola rebolar por vários minutos, chutoua para o alto. A bola voltaria ao seu peito numa matada perfeita, mas que nada, 
Inferninho apertou o gatilho e a bola caiu já sem vida. Martelo e Tutuca gargalharam; Inferninho, porém, ficou sério, deixando escapar um olhar irado que dava continuidade ao som do tiro. Impôs silêncio atirando suas retinas no rosto de cada um num lance rápido como se fossem todos culpados da desgraça que era sua vida. $\mathrm{Na}$ verdade, a morte da avó servirá apenas como pretexto para a escolha feita. O caminho do crime significava para ele uma forma de não se submeter à escravidão. Desde pequeno, seus heróis eram bandidos, aos quais fazia questão de servir. Pensava que sua libertação viria com a aquisição de um 'berro' 'para ficar rico no asfalto'. (LINS, 2002: 24)

O revólver será o prolongamento de seu corpo, garantia de sobrevivência. Mesmo diante das situações mais insignificantes, o personagem desafiará a autoridade e o poder. Por esse motivo, Inferninho "tratava o três oitão como quem cuida da solução de todos os problemas". A importância de uma arma, aliás, fora lição aprendida com a mãe, desde cedo: “Bandido sem revólver é como puta sem cama. Lembrou-se dessa lição cavernosa e simples que sua alma, ainda menina, aprendera com sua mãe quando estava sem quarto na zona e o pai sem um revólver para assaltar" (LINS, 2002: 133). O "ferro" era indispensável para se defender dos outros bandidos, mas também, e principalmente, da polícia, vista pela população como inimigo comum. Foi pelas mãos de um policial que o bandido encontrou a morte, ainda e sempre sob o signo da violência. Para quem enfrentara a vida como uma guerra diária, a morte era o encontro com a paz que fora incapaz de conhecer. O mundo estivera sempre sob a mira de seu revólver. Fez da paz um "sistemático anúncio de guerra. Assim viveu, assim morreu".

Tutuca tinha menos motivos de revolta do que o amigo. Oriundo de uma família de crentes, percebeu, desde cedo, para desgosto dos pais, que a religião não resolveria o problema da exclusão, pois "Deus ficava muito longe". (LINS, 2002: 26). Na opinião dos vizinhos, nada justificava a atitude do bandido:

Tutuca não era feio, [...] era um menino bem tratado, pois tinha um pai que não bebia, um homem que vivia da casa para o trabalho, do trabalho para casa, e o filho ficava ali com aquela cara de cão raivoso. Por qualquer coisinha queria dar tiro nos outros, assaltava moradores, currava as meninas do pedaço. Era um bom filho-da-puta. (LINS, 2002: 27) 
Para ele, assaltar era uma questão de sobrevivência, até porque "ficar duro" era o mesmo que ficar à mercê de uma polícia truculenta e corrupta. Que direitos dá o poder? $\mathrm{O}$ que resta àqueles que se vêem alijados dele, a partir de uma condição de origem? Tutuca impôs sua autoridade e prestígio não pela via da aceitação social, mas pela força da bala. Para conservá-los, apelou também para o sobrenatural, fazendo um trato com o Diabo. Confiando nessa força adicional e gozando da garantia de impunidade, o bandido ultrapassa todos os limites humanos. O pagamento acertado no pacto com as forças do mal era uma barganha em face das vantagens de que passava a desfrutar. $O$ compromisso de mandar uma alma para o Inferno sempre às segundas-feiras e a promessa de "não deixar furo" com o Demônio valiam a proteção que experimentava, e que somente o mal poderia proporcionar. Mas até na esfera do sobrenatural há regras. E a transgressão podia implicar a morte. Assim, a justiça se faz em nome da violação de um código de honra. Não daquele tacitamente aceito por uma parte da sociedade, mas de um outro que está acima da ética porque não se coloca sob a égide da justiça dos homens, do bem ou da verdade. Esse código, não questionando a legitimidade dos objetivos a serem alcançados, concede a obtenção dos desejos do pactuante, mas inscreve compromissos que não podem ser rompidos. Tutuca recusa o código social inerente a um sistema do qual se vê excluído e pactua unicamente com a parte que lhe concederá o que importa para sobreviver. Embora o trato sobrenatural se tenha rompido sem a participação consciente do bandido, o ajuste de contas terá de ser feito. Ele é morto em decorrência da quebra de um contrato. Aquilo que no bandido parecia conseqüência de um "instinto ruim", o ódio e a revolta que moldam suas ações, as maldades e os excessos cometidos contra os seus semelhantes, enfim, aquilo que aos vizinhos parecia meramente gratuito, poderá encontrar uma justificativa na compensação às privações, como se percebe nas seguintes palavras de Freud, a propósito da exclusão e da injustiça social inerentes às sociedades modernas:

Se nos voltarmos para as restrições que só se aplicam a certas classes da sociedade, encontraremos um estado de coisas que é flagrante e que sempre foi reconhecido. É de esperar que essas classes subprivilegiadas invejem os privilégios das favorecidas e façam tudo o que podem para se liberarem de seu próprio excesso de privação. Onde isso não for possível, uma permanente parcela de descontentamento persistirá dentro da cultura interessada - o que pode conduzir a perigo- 
sas revoltas. Se, porém, uma cultura não foi além do ponto em que a satisfação de uma parte e de seus participantes depende da opressão da outra parte, parte esta talvez maior - e este é o caso em todas as culturas atuais -, é compreensível que as pessoas assim oprimidas desenvolvam uma intensa hostilidade para com uma cultura cuja existência elas tornam possível pelo trabalho, mas de cuja riqueza não possuem mais do que uma quota mínima. Em tais condições, não é de esperar uma internalização das proibições culturais entre pessoas oprimidas. Pelo contrário, elas não estão preparadas para reconhecer essas proibições, têm a intenção de destruir a própria cultura e, se possível, até mesmo de aniquilar os postulados em que se baseia. (FREUD, 1997: 20-21)

Dos três amigos, apenas Martelo consegue redenção, que encontra pela via da conversão religiosa. A consciência de que a vida na clandestinidade não compensava e que a iminência da morte o espreitava em todos os becos da favela faz o bandido optar pela vida, procurando na religião a resignação que nunca experimentara. O bandido abre mão da ação em nome da paz e da crença na utopia, representada pela esperança de uma vida melhor em outro mundo.

Os outros dois capítulos do romance são dedicados a dois bandidos: Pardalzinho e Miúdo, companheiros inseparáveis desde o tempo de criança, quando assaltavam juntos no centro da cidade. Contudo, apenas a amizade os une, porque cada um tem um modo muito particular de encarar o mundo. O exemplo dos bandidos encantava a muitas crianças da Cidade de Deus, que cometiam pequenos delitos e queriam compartilhar suas vitórias com os "mestres". Dentre elas, Inho, líder de um bando que agia no centro da cidade:

Inho, o que mais arrumava dinheiro, era o líder do bando. Mentia para os amigos, numa tentativa de ganhar respeito, dizendo já ter mandado mais de dez pro inferno nos assaltos feitos sozinho. Admirava Inferninho, mas tinha adoração por Grande, bandido que mandava na Macedo Sobrinho. (LINS, 2002: 51)

Desde pequeno destilava sua revolta contra o mundo e alimentava a ambição de ser o maior, de dominar, como outros bandidos famosos:

Quando tomou enfim a boca que pertencera a Grande - o bandido que dominava na Macedo Sobrinho - Inho passou a se chamar Zé Miúdo. Não hesitava 
em matar. Para ele, matar era sempre uma forma de aumentar o prestígio e o poder. Assim foi quando matou 6 pessoas com a desculpa de estar vingando a agressão sofrida por Pardalzinho. Este, embora bandido, no fundo, só pretendia ser aceito. Por isso mudou o "visual" e virou playboy. Ele tinha consciência de que quem não domina a linguagem do poder estará irremediavelmente excluído. (LINS, 2002: 238)

Depois da morte de Miúdo, o tráfico assumiu uma dimensão social que não conhecera antes. Tomando o lugar das instituições de assistência à pobreza, os traficantes ganharam mais importância nas comunidades. Tigrinho explicava as novas atribuições da organização. Como nas grandes empresas, era preciso expandir as atividades e assumir o papel que antes cabia às instituições oficiais:

Com esses setenta por cento pagariam, além de certa quantia por semana, plano de saúde para os principais soldados e olheiros, ajudariam os trabalhadores da área na hora em que eles estivessem precisando, comprariam mais armas, contratariam um advogado para trabalhar para a quadrilha e tirariam o dinheiro para a reposição da mercadoria. (LINS, 2002: 377)

A atuação de Miúdo, mais inconseqüente, deu lugar a uma ação mais consciente, refletindo a adaptação que os novos tempos exigiam. Objetivando a eficácia, como forma de aumentar os lucros, o tráfico se expandiu enormemente e hoje forma uma complexa rede que se estende dos gabinetes às favelas e aos presídios, envolvendo milhares de pessoas, seduzidas pelo poder, mas para a maioria ainda representa uma alternativa de sobrevivência, embora também uma forma de opressão.

Assim como nos demais lugares, a vida em comunidade requer o respeito a um conjunto de regras que devem ser observadas. Em Cidade de Deus, essas normas são impostas a todos os moradores, independentemente da idade. A transgressão é passível de punição, inclusive com pena de morte aplicada a crianças. Algumas dessas regras são aceitas pelos membros da comunidade, baseadas nos usos e costumes, outras são impostas pelo poder paralelo, que as legitima pela força das armas. Dentre os delitos cometidos, estão os chamados crimes de "honra e paixão", para os quais a aplicação de penas pela 
parte ferida goza de certa legitimidade entre os moradores. A parte traída tem o "direito de vingar a honra com sangue", aplicando, segundo o caso, penas que variam de uma surra à morte da outra parte, ou mesmo vingança mais bárbara, dependendo da parcela de ódio e da crueldade do algoz: "As mulheres têm de sofrer todas as mazelas da eternidade quando fodem com outro homem. Aquela filha-da-puta tinha de pagar caro" (LINS, 2002: 69).

Também a pena de morte é prevista nos casos de delação para que outros não sigam o mau exemplo. Ainda segundo o código de ética dos bandidos, "não se arruma bronca" no lugar onde se mora para não atrair a atenção da polícia e atrapalhar a ação dos traficantes. Assaltos a membros da comunidade são terminantemente vedados: "Passistinha sempre falava que bronca era pra ser feita na área dos outros" (LINS, 2002: 47). As transgressões podiam ser perdoadas eventualmente, caso os novos “juízes” concedessem. $\mathrm{Na}$ maioria dos casos, eram impostas condições ao infrator, que poderia se livrar do castigo prestando pequenos favores à organização e ficando, assim, quite com ela:

Há aqueles que matam ou assumem a autoria de assassinatos para se livrarem de morrer por terem estuprado, terem saído com mulheres, aproveitando que seus maridos estavam presos, assaltado moradores do lugar onde moravam, enfim, sabiam que se chegassem àquele presídio com alguma infração ao código de ética da organização, só lhes restariam três opções de pena: matar, ser morto ou assumir a responsabilidade dos crimes. (LINS, 2002: 235)

A incriminação parece ser o principal substituto para o crescente desaparecimento dos dispositivos do estado de bem-estar nas sociedades de consumo. O problema dos pobres é remodelado como questão da lei e da ordem e as verbas públicas antes destinadas à recuperação de pessoas temporariamente desempregadas são hoje empregadas na construção e modernização tecnológica das prisões ou outros equipamentos punitivos e de vigilância. Convertidos nos proscritos de uma sociedade de consumidores seduzidos, transformados em uma classe baixa sem perspectiva na sociedade e privados dos meios legalmente reconhecidos de acesso aos bens de consumo - considerados valores supremos da vida agradável -, os pobres tendem a lançar mão das drogas, sucedâneas ilegais, equivalentes aos instrumentos do êxtase consumidor dos ricos. Também tendem, de quando em quando, a iniciar a politicamente negligenciada "redis- 
tribuição de riqueza", atacando os bens particulares mais próximos e assim fornecendo ao Estado mais uma prova do estreito vínculo entre marginalização e criminalidade, sutilmente usada em apoio à incriminação da pobreza. Em Cidade de Deus a identificação entre miséria e criminalidade é óbvia. Em relação à polícia, vige a lei do mais absoluto silêncio guardado pela população, que, invariavelmente, não vê nada, não ouve nada e não sabe de nada: "Nada numa favela passa despercebido, para tudo tem sempre alguém que vê e delata. Somente para a polícia a lei do silêncio funciona" (LINS, 2002: 344). Os policiais dispensam aos trabalhadores pobres o mesmo tratamento que é dispensado aos bandidos. Desse modo, é nítida a oposição entre as forças responsáveis pela manutenção da lei e da ordem e a população. A polícia não garante a segurança do cidadão, ao contrário, valendo-se da prerrogativa que a lei lhe confere, age livremente, usando os instrumentos de opressão em proveito próprio, quase sempre extrapolando suas atribuições e reproduzindo o ponto de vista de uma sociedade que despreza os miseráveis. No romance, as forças de coerção são representadas por dois policiais corruptos e truculentos - Cabeça de Nós Todo e Belzebu - que achacam igualmente bandidos, traficantes e trabalhadores, cujos pequenos delitos se prestam a complementar o salário que recebem. Assim como os bandidos, os policiais estão envolvidos em atividades criminosas, como a venda de armamentos e munição. Tanto quanto aqueles, esperam um dia "rebentar a boa", confiscando o produto de um grande assalto que lhes possibilite a libertação e livre trânsito para uma aposentaria sossegada. Em nome da lei, a polícia aplica ela própria a pena de morte àqueles que considera perniciosos à sociedade, exatamente com a mesma convicção de quem percebe a necessidade de limpeza de um ambiente sujo:

Combinaram tudo ali sem fazer uso de palavra. O primeiro tiro da pistola 45 do sargento atravessou a mão esquerda de Pelé e alojou-se em sua nuca. A rajada da metralhadora de Belzebu rasgou o corpo de Pará. Um pequeno grupo de pessoas tentou socorrê-los, porém Belzebu proibiu com outra rajada de metralhadora, desta vez para o alto. Aproximou-se dos corpos e desfechou os tiros de misericórdia. (LINS, 2002: 94)

A situação do policial é homóloga à do bandido até no que respeita às relações interpessoais, já que tanto um quanto outro estão excluídos do mercado 
consumidor. O nível social é o mesmo; a origem e as histórias de vida se parecem. A semelhança entre as duas classes é de tal ordem, que a mulher do policial tem as mesmas inseguranças da mulher do bandido:

Definitivamente não dormiria mais com um homem que tinha a arma como parte do corpo. Homem sem paz de espírito, assassino. [...] Ser mulher de PM era um fato afugentador de amizades. Vivia trancada em casa. E se reclamasse muito entrava na porrada. (LINS, 2002: 145)

O nível de alienação dos dois grupos também é semelhante. A polícia é incapaz de perceber que representa e defende os interesses de uma classe da qual está igualmente excluída. Institucionalizando a violência, investe contra sua própria classe e, ambiguamente, coloca-se na situação de vítima e algoz.

Em todo o romance, somente em poucos momentos o discurso ideológico é transparente. Surge na boca de um bandido, o Grande, que percebe o paradoxo na situação do policial, voltando o seu ódio contra os brancos e contra os policiais, que reconhece estarem a serviço de uma sociedade branca e injusta: "Tinha prazer em matar branco, porque o branco tinha roubado seus antepassados da África para trabalhar de graça, o branco criou a favela e botou o negro para habitá-la, o branco criou a polícia para bater, prender e matar o negro" (LINS, 2002: 176). Também no discurso da enunciação se questiona se "pode realmente haver paz plena para quem o viver fora sempre remexer-se no poço da miséria”.

Segundo Freud:

Tal como para a humanidade em geral, também para o indivíduo a vida é difícil de suportar. A civilização de que participa impõe-lhe certa quantidade de privação, e outros homens lhe trazem outro tanto de sofrimento - seja apesar dos preceitos de sua civilização, seja por causa das imperfeições dela. A isso se acrescentam os danos que a natureza indomada - o que ele chama de destino - lhe inflige. Poderse-ia supor que essa condição das coisas resultaria num permanente estado de ansiosa expectativa presente nele e em grave prejuízo a seu narcisismo natural. Já sabemos como o indivíduo reage aos danos que a civilização e os outros homens lhe infligem: desenvolve um grau correspondente de resistência aos regulamentos da civilização e de hostilidade para com ela. (FREUD, 1997: 27) 
Em Cidade de Deus a violência é o alimento consumido cotidianamente pela população. Institucionalizada ou não, se alastra como pólvora e explode em todos os becos, manchando de vermelho a paisagem do lugar. Por "motivos miseráveis", as crianças são obrigadas a cometer pequenos delitos, quer para aplacar a própria fome, quer por uma imposição das próprias famílias, que muitas vezes delegam a elas a tarefa de alimentá-las:

Eram conhecidos como anjos, porque todos eram nascidos na Cidade de Deus [...]. Famintos devoravam três galetos conseguidos em um assalto feito numa lanchonete no Largo da Taquara, aonde chegaram armados de fome até os dentes. (LINS, 2002: 245)

Quando não assaltavam o comércio próximo à favela, as crianças investiam contra os moradores, tão miseráveis quanto elas. Diante da fome, a ética se cala e o único valor a ser observado é a lei da sobrevivência. As transgressões cometidas eram passíveis de punição, já que os traficantes não queriam ser importunados pelo movimento de carros policiais na favela. Não há qualquer saída: ou se morre de fome ou se morre de bala, castigo imposto pelos traficantes:

Não pode roubar ônibus da favela! A gente já tinha falado! Vai passar no corredor polonês! Os quadrilheiros formaram fila dupla, obrigaram os ladrões a passarem três vezes entre eles, dando-lhes coronhas sem nenhuma piedade. Bigolinha, de nove anos, desmaiou. Miúdo achou que tudo não passava de truque para parar de apanhar e por isso deu-lhe chutes e mais coronhadas. Em seguida, dando gargalhadas, descarregou sua pistola nove milímetros no corpo do menino. (LINS, 2002: 244)

Desde pequenas, as crianças se habituaram a conviver com a violência que não permite a manutenção de laços libidinais, às vezes, nem mesmo entre membros da mesma família. Assim é que, mais tarde, elas voltam sua hostilidade primeiramente contra os que lhes são mais chegados e posteriormente contra o mundo:

Em seu apartamento, antes de começar o tiroteio, Tuba havia dado um soco na cabeça de sua mãe, dois pontapés no ventre, uma cabeçada na boca e uma 
coronhada na nuca, levando-a ao chão. [...] Já havia lhe avisado que se ela insistisse em mandá-lo arrumar isso ou aquilo iria lhe enfiar a porrada. A bruta não acreditou. (LINS, 2002: 357)

Por outro lado, são os laços libidinais que mantêm os grupos unidos. Mas o que garante a fidelidade ao líder é o medo que infligem e o respeito de que gozam. Nenhum membro ousa desafiar as ordens do líder, sob pena de pagar com a vida, ainda que a vítima seja o próprio irmão:

Foi acordado com o cano do revólver na nuca, foi levado para a rua, sua única defesa foi ameaçar o irmão:

- Se mamãe souber que tu me matou, ela vai ficar puta contigo!

- Foda-se! Quem mandou tu virar alemão?

Alexandre foi levado para a beira do rio e o próprio irmão desfechou três tiros naquele corpo de apenas dez anos. (LINS, 2002: 393)

A estreita convivência com a brutalidade, aliada ao esvaziamento dos valores, a banalização da morte, o modelo negativo, entre outros fatores, facilita a instauração da violência em cadeia que se inaugura não só com a guerra entre as quadrilhas de Miúdo e Bonito, mas entre componentes de grupos menos poderosos, todos ansiosos pelo controle do tráfico na área. Alguns se engajaram na luta pelo que consideram uma causa justa, como vingar a morte de um parente ou de um amigo; outros, por motivos pueris, outros, ainda, sem qualquer motivo. Houve casos em que os futuros quadrilheiros não tinham crime algum para vingar, contudo, entravam na guerra porque a coragem aliada à disposição para matar exibida pelos bandidos lhes conferia um certo charme aos olhos de algumas garotas. Elas admiravam fulano ou sicrano por estarem empenhados em defender a área, eles se sentiam poderosos e enfim compreendidos. Jovens insuspeitos tornavam-se bandidos e guerreavam, às vezes, somente com um pedaço de pau na cintura enquanto aguardavam o seu revólver:

Antigamente, comentavam pasmados os moradores, somente os miseráveis, compelidos por seus infortúnios, se tornavam bandidos. Agora estava tudo diferente [...] guerreavam por motivos banais: pipa, bola de gude, disputas de 
namoradas. [...] A guerra, assim, tomou proporções maiores, o motivo original não significava mais nada. (LINS, 2002: 350)

A violência vitima toda a população, obrigando mesmo quem não é bandido a tomar parte na guerra, como ocorreu com Zé Bonito, que entrou na criminalidade por falta de opção. Diante da morte do irmão pela quadrilha rival, só restava a ele alimentar o espírito com imagens que fazem crescer o ódio, para suportar a dor de uma realidade que corta mais fundo que talho de machado.

Algumas características comuns ligam os membros da quadrilha de Miúdo. Todas elas concorrem para a manutenção da violência: "Eles eram os americanos, e os inimigos, alemães. Todos eram filhos de pais desconhecidos ou mortos, alguns sustentavam a casa, nenhum havia terminado o primário" (LINS, 2002: 323).

O narrador reinventa a única linguagem possível para cantar um território esquecido por Deus e em que a lei da bala funda seus próprios direitos. Inaugurando uma sintaxe da violência, o romance transpõe mimeticamente para a linguagem o que não pode ser ocultado pela realidade. Assim, a violência contagia a própria natureza, que se tinge de vermelho: "Alguns bandidos atiraram no defunto, o sangue jorrou forte, fazendo cair mais rápido e tornando mais rubro o crepúsculo de outubro" (LINS, 2002: 146).

A presença da morte interditando o verbo constrói a homologia entre a intransitividade e o sujeito sem voz, calado para sempre: "- Passistinha morreu, Passistinha morreu, Passistinha morreu!!! Deu-se um corte na manhã, oriundo de uma oração de verbo intransitivo e sujeito morto (LINS, 2002: 91).

A imagem da metralhadora disparando tiros como uma gargalhada fornece à narrativa um tom sinistro que ironicamente reflete o contexto: "A gargalhada da metralhadora esburacava muros, espantava os pardais e todos os seres humanos que presenciavam ou escutavam o barulho daquela ação" (LINS, 2002: 97).

Assim como Cidade de Deus inscreve uma sintaxe da violência, também promove a inauguração de um novo regime semiológico, que possibilita a comunicação. Esta se dá quer por sinais, sonhos e avisos, quer por gestos ou objetos, denunciando um código peculiar aos membros de uma comunidade. Metáforas tomam o lugar de expressões faciais, provocando o deslizamento entre regimes semióticos diversos: "O milagre da conversão mudou as me- 
táforas de seu semblante. A paz estava agora presente em todas as coisas" (LINS, 2002: 129). Avisos, sonhos, constituem uma forma de saber e propiciam a comunicação com outras dimensões:

- Vocês tão onde?

- Isso não interessa agora, porém se não quiser vim para a nossa companhia é melhor deitar Cabeça de Nós Todo - finalizou Tutuca, que foi se transformando em fumaça junto com seus parceiros. A fumaça permaneceu um tempo imóvel, em seguida se transformou numa poça de sangue, onde Inferninho viu seu corpo estrebuchando. O bruto acordou gritando. (LINS, 2002: 132)

A linguagem do corpo enviava uma mensagem aos destinatários. Um cadáver caído de bruços significava que o morto pedia vingança: "No velório, sua mãe foi consolada pelos amigos. Diziam-lhe que o assassino também morreria em breve, porque seu filho caíra de bruços" (LINS, 2002: 116).

$\mathrm{O}$ tráfico impunha um código particular como forma de escapar às garras da lei; assim, as pipas inauguravam significados que podiam ser facilmente decodificados pelos membros das quadrilhas: "Por isso aos sábados, dia de maior movimento, pediam a Chinelo Virado, então com dez anos, para colocar a pipa no alto e debicar para a esquerda caso a polícia aparecesse de repente" (LINS, 2002: 101).

Paulo Lins ${ }^{1}$ identifica na marginalidade uma extensão do arbítrio, que se impõe para oprimir os excluídos. Aponta as ações das facções criminosas como fator de desagregação no seio de uma sociedade que já vive naturalmente confinada em guetos e sofre igualmente a opressão de uma polícia despreparada, a serviço de um Estado injusto. Cidade de Deus retrata em linguagem contundente mais do que uma realidade sinistra. A ficção, tomando o lugar da realidade, questiona as imagens de felicidade e bem-estar veiculadas pela indústria de imagens, mostrando que a liberdade individual é um mito nas sociedades que apostam na exclusão.

1 “Cultura da violência. Quem são os culpados?”. Jornal O Globo, 16 de junho de 2002. 


\section{Referências Bibliográficas}

BAUMAN, Zygmunt. O mal-estar da pós-modernidade. Trad. Mauro Gama e Cláudia Martinelli Gama. Rio de Janeiro: Zahar, 1998.

FREUD, Sigmund. O futuro de uma ilusão. Trad. José Octávio de Aguiar Abreu. Rio de Janeiro: Imago, 1997.

Psicologia de grupo e análise do ego. Edição eletrônica das obras psicológicas completas de Sigmund Freud. Rio de Janeiro: Imago, s. d. v. XVIII.

HARVEY, David. Condição pós-moderna. Uma pesquisa sobre as origens da mudança cultural. Trad. Adail Ubirajara Sobral e Maria Stela Gonçalves. 11. ed. São Paulo: Loyola, 2002.

LINS, Paulo. Cidade de Deus. 2. ed. São Paulo: Companhia das Letras, 2002. 